\title{
A report on serpentinites in the context of heritage stone resources
}

Department of Geology, Plaza de la Merced s/n, University of Salamanca, 37008 Salamanca, Spain. E-mail: mdp@usal.es

\section{Introduction}

Serpentinites are metamorphic rocks that are produced by low grade metamorphism or hydrothermal alteration of ultramafic igneous rocks. They have been used for many centuries in the construction of major cultural and religious symbols. The serpentinization of igneous rocks is a widespread process, present in most ultramafic massifs, in which the original rock changes its mineralogical composition during phases of hydration (Moody, 1976; O’Hanley, 1996). The process can take place through shearing and can also affect the rock partially or totally. Today serpentinites are commonly used in construction around the world in view of their attractive structures, colours and patterns, mostly in various shades of green. But they have also been utilised in monuments. The high porosity that can be present in serpentinites (up to $10 \%$ in the Appenine serpentinites (Malesani et al., 2003) can cause major problems of alteration and in durability, both indoors and outdoors, and the deterioration of the rock requires that a replacement material is quickly found. Knowledge of the composition of the rock and the provenance of the deteriorated tiles can help to preserve the exterior visual aspect of a building that has to be restored. This is vital in the case of monuments and the characterization of serpentinites should be the first step in a planned restoration of a deteriorated part of a historical building. Therefore, the importance of appropriate information on serpentinites as heritage stone resource (Cooper, 2010).

\section{The objectives}

Serpentinite is an appealing rock, very commonly applied as dimension stone. However, not all serpentinites possess the essential properties that are necessary for use in construction. Most commercial serpentinite originates from Pakistan, India (Rajasthan Green), Italy (Verde Alpi, Verde Polcevera, Verde Prato), United States (Vermont Verde Antique), Guatemala (Verde Guatemala), Portugal (Verde Donai) and Spain (Verde Macael, Verde Pirineos). Differences in climate can lead to misbehaviour of serpentinites and in some cases historical buildings that used this kind of rock in their construction suffer from extreme deterioration. Many of these buildings can be related to local architectonic heritage and their disappearance will imply a considerable cultural lost. Learning from this negative experience is necessary to avoid the same effect with contemporary construction. Knowledge of the rock's intrinsic characteristics will help to choose a suitable replacement stone in case of restoration of monuments as well as for new construction. Besides, some serpentinites can be nominated as heritage stone resource to protect their availability for restoration of architectonic heritage.

Observations on serpentinites from Galicia (northwest Spain)
(Figs. 1 and 2) shown that the present state and the visual effects produced by the evolution of the rock with weathering is probably very different from what sculptors, constructors and architects expected when choosing this natural stone for their purposes. Extrapolation of these observations to other utilized serpentinites can serve for a better use of this rock in the future.

\section{The facts}

Different tools can be used for characterization of serpentinites: optical microscopy, x-ray diffractometry, geochemical analysis and physical and mechanical testing (Pereira et al., 2004; 2010). Considered together these methods can constitute an excellent tool both to characterize the rocks and to identify their origin for a proper use in a restoration work.

Some serpentinites have been quarried since ancient times for building purposes. Such are the cases of serpentinites from the Italian Alps, the different areas of the Rajasthan or Moeche and Macael, in Spain (Pereira et al., 2004, 2010, Fig. 1). These serpentinites occur in different varieties, depending on the degree and type of weathering. Some are transformed partly or totally into carbonates and some are transformed primarily into talc (Fig. 3). Examples of the latter can be found worldwide, utilised to build façades, local symbols and details that adorn many historical buildings (i.e. family coat of arms, Fig. 2).

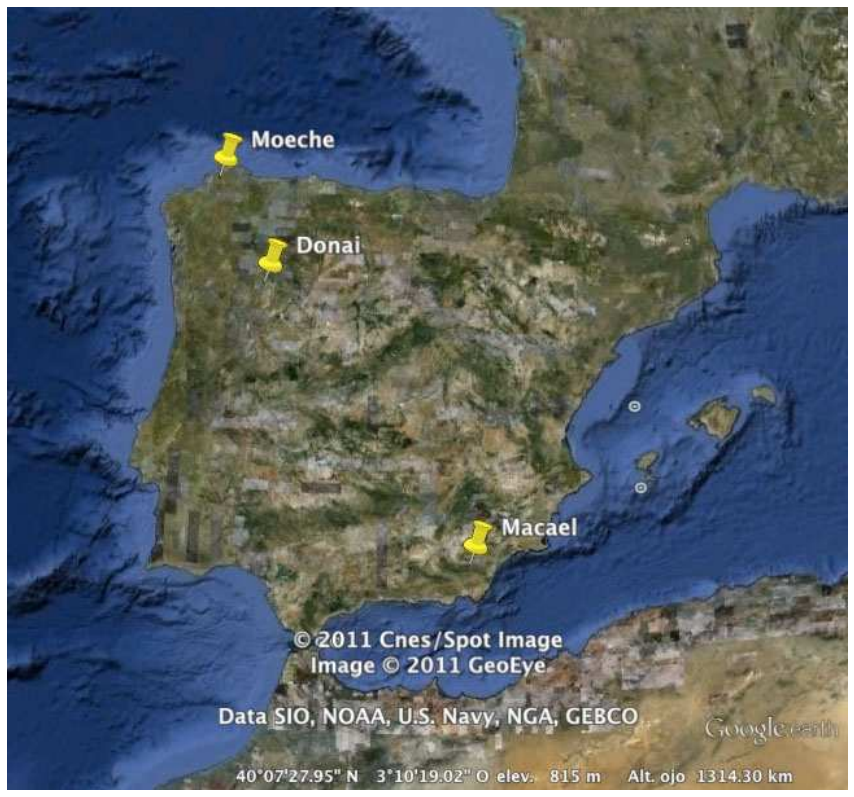

Figure 1. Location of serpentinite quarries in Iberia: Verde Pirineos (Moeche, Galicia, Spain), Verde Macael (Macael, Andalucía, Spain), Verde Donai (Donai, Portugal) 

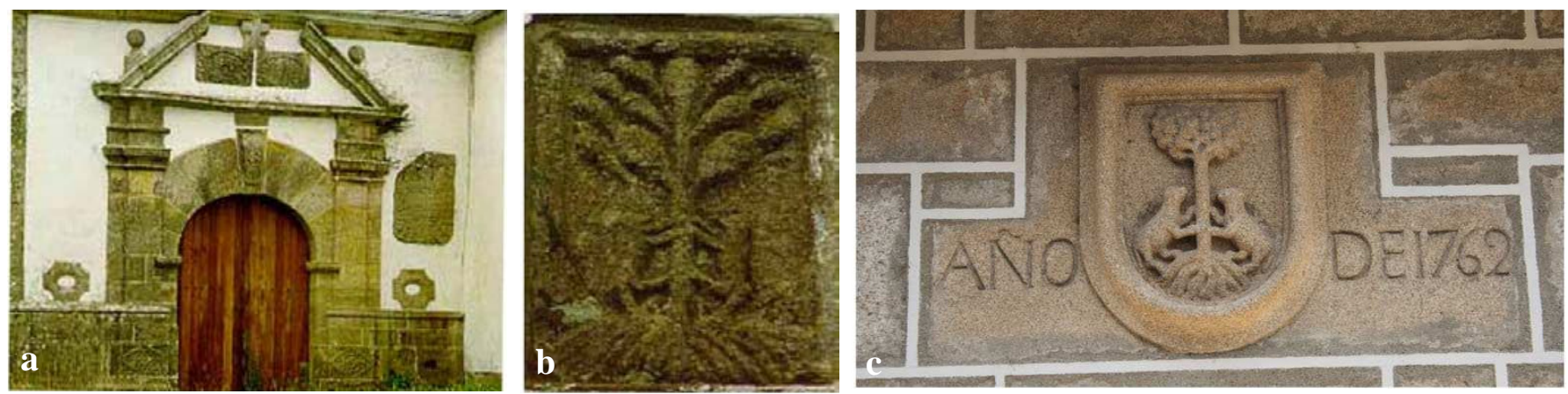

Figure 2. Examples of historical architecture in the Moeche area (Galicia, Spain): (a) San Xurxo church (s. XVIII) (http://www.fometur.com/ ?id=51526\&cat=1\&p=166\&s=1); (b) Osorio family coat of arms engraved in serpentinite; (c) Osorio coat of arms engraved in granite. Differences in conservation in both figures due to the lithology used for the engraving can be observed.

Other most widespread lithologies were avoided due to the difficulties for working if they were tougher than serpentinites. In this context, serpentinites provide a practical and attractive alternative. But in some cases, results along the years have proved this to be a mistaken practice. Taking the Spanish examples, most Galician quarries were closed down many years ago, probably because of undesirable rock characteristics that were revealed when used in construction (Pereira et al., 2010). Now we find that buildings utilising serpentinite, either in their construction or as ornamentation, have used imported rocks from India, Pakistan or Guatemala. These products are sold under various commercial names, depending on the colour or structures, but most of them may be found in sales catalogues under the "marble" section, labelled as "Green marble". The reason for this denomination results from the high degree of mineral transformation in these rocks to carbonates; most of the serpentine is now carbonate and, from a petrographic point of view, they can be classified as transformed carbonate rocks. However, some remnants of the original assemblage of minerals can be found (i.e., olivine, pyroxene, spinel-group minerals), and the evolution of these minerals following alteration can be very different, either to serpentine, to carbonates or to talc.

It is a striking feature that even where serpentinites are pervasively transformed into carbonates, they maintain their appearance in colour and structures. Serpentinite tile replacement in modern buildings can lead to misuse if the correct natural stone is not selected (Pereira et al., 2004). This outcome is not a severe problem in this kind of building, but it is an unacceptable result if dealing with an historical building (Malesani et al., 2003). A detailed characterization of a natural stone can provide an unambiguous provenance for this stone, which is very important when a restoration of a major monument takes place.
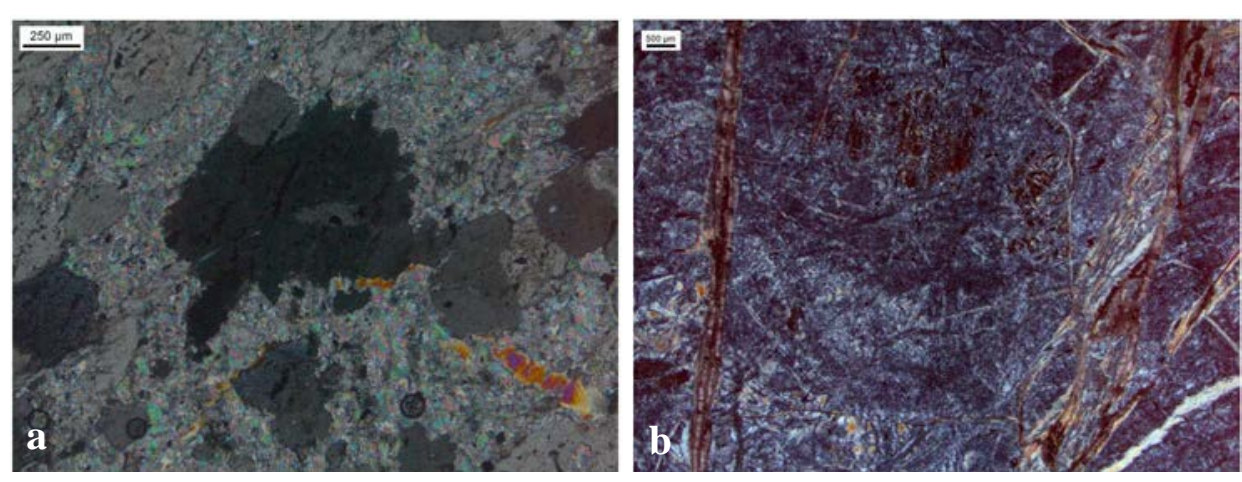

Some historical buildings are deteriorating badly and soon they will need restoration or replacement. It is advised to ascertain whether it is worthwhile to use the same original natural stone and, if so, which one to use.

\section{Learning from errors}

When ultramafic rocks contain a high percentage of water, we conclude that these rocks are altered. Weathering can be due to surface exposition of the rock to meteoric fluids or fluids coming from other origins, and the process can take place in outcrop or once the rock has been emplaced for building.

The differences in mechanical response are strongly dependent on the mineralogy and the structure of the rock. The Spanish Verde Pirineos is a rock made up primarily of serpentine, cross-cut by a few veins of chrysotile and carbonate. Most of the original mineralogy [forsterite, enstatite, augite, metamorphic tremolite] has been transformed to lizardite or further into talc and/or magnesite. Other carbonates (dolomite) are found mainly in shears and veins crosscutting the fabric of the rock. These serpentinites have proved to be softer and more fragile than those that are cemented (i.e. Rajasthan Green, Verde Macael), susceptible to low values for compressive strength, and do not achieve the requirements for use as dimension stone in most of their uses. Cemented serpentinites have demonstrated to be more resistant to further alteration and do satisfy building specifications. It seems that carbonates act as an ideal cement to hold rock components together, unlike the uncarbonated samples.

However, despite the bad behaviour that this natural stone some new buildings are still using it in their construction. To prevent

Figure 3. Microscopic examples of serpentinites transformation: a) Serpentinite is totally provide in most instances is inadequate. transformed into talc and carbonate; b) Serpentinite do not present any transformation. The For some commercial serpentinites, reddish fibbers are chrysotile, another serpentine phase. unrealistic claims equal to the hardness of 
most granites (just over 6 on the Moh's scale of hardness) have been offered in cases where constituent minerals are related to talc (hardness 1) and chlorite (hardness around 2 1/2). In this situation, stone suppliers require a thorough petrographic study to be included with sales information. A close relationship between scientists, architects and suppliers would be desirable.

This report highlights the need of research on the methods of building with as well as restoration using serpentinites. Choosing carbonate-cemented serpentinites could solve some behavioural problems. As well, promoting research in reinforcements or methods of consolidation would prevent the disappearance of important cultural value like the Gandharan sculptures, originally from Peshawar Valley in Pakistan, and now displayed outdoors in southwest England (Proudfoot et al., 1988; Selwitz, 1992). More investigations along this line are needed because the importance of preserving cultural and architectonic heritage. In this context, some of the mentioned serpentinites from Rajasthan could be designated at some future time as Global Heritage Stone Resource (Cooper, 2010).

The conclusions of misbehaviour of some serpentinites can be applied to all natural stones, demanding their detailed study before utilisation in civil construction or restoration work.

\section{Acknowledgements}

This work was supported by the project CGL2010-18579/BTE from the Spanish government. Barry Cooper is acknowledged for his advise on the subject and for his help in the English revision. An anonymous reviewer is acknowledged for his/her advise in reorganizing the report.

\section{References}

Cooper, B., 2010, Toward establishing a "Global Heritage Stone Resource” designation. Episodes, v. 33, no. 1, pp. 1-4.

Malesani, P., Pecchioni, E., Cantisani, E. and Fratini, F., 2003, Geolithology and provenance of materials of some historical buildings and monuments in the centre of Florence (Italy). Episodes, v. 26, no. 3, pp. 250-255.

Pereira, D., Peinado, M., Blanco, J.A., Yenes, M., Fallick, A., Upton, B., 2004, Serpentinite: a potential natural stone in Spain. In: R. Pickryl (Ed.) Dimension stone, Balkema, Taylor and Francis Group, London, pp. 85-87.

Pereira, D., Peinado, M., Yenes, M., Monterrubio, S., Nespereira, J. and Blanco, J.A., 2010, Serpentinites from Cabo Ortegal (Galicia, Spain): a search for correct use as ornamental stones”. Geological Society of London, Special Publication, no. 333, pp. 81-85.

Proudfoot, T., Garland, K. and Larsen, J., 1988, The examination and conservation of a collection of Gandharan scuptures from Anthony House, Cornwall. The Conservation of Far Eastern Art, IIC, Kyoto Conference, pp. 113-120.

Selwitz, Ch., 1992, Epoxy resins in stone consolidation. In: I. Averkieff (Ed.), The Getty Conservation Institute Publications.

\section{CALL FOR PAPERS}

Episodes is a quarterly science and news journal of the International Union of Geological Sciences (IUGS). It focuses on the publication of results of scientific research and other information addressing issues of interest to the global Earth science community. Special emphasis is given to topics involving geological aspects of population growth and economic development and their resulting impacts on or implications for society. As the principal publication of the IUGS, Episodes also carries information about IUGS scientific programs and activities to the extent necessary to communicate effectively with the worldwide IUGS constituency.

Contributions of the following types of manuscripts are solicited:

- Review papers

- News and views

- Letters to editor

Information on training courses (especially those geared to participants from developing countries)

- Noteworthy new publications, including national or regional geological maps

Episodes also invites photos or other images for the front cover. Photos must be of high technical quality and tell an interesting geological story. A color transparency and one color print (at least $9 \mathrm{~cm}$ x $12.6 \mathrm{~cm}$ ) are required for submission, which should be supplemented with a short explanatory paragraph (no more than 100 words).

Please address all contributions to: Dr. M. Jayananda

Editor, Episodes

Email: episodes.editor@gmail.com 